\title{
PERSPECTIVAS DA PÓS-GRADUAÇÃO EM DIREITO NO BRASIL - 50 ANOS DEPOIS
}

\author{
Vicente de Paulo Barretto ${ }^{1}$ \\ André Luiz Olivier da Silva ${ }^{2}$
}

O sistema da pós-graduação em Direito no Brasil ao completar 50 anos, como todo adulto meio centenário, exige um momento de reflexão, não, exclusivamente, sobre a sua história, mas sobretudo a respeito de suas perspectivas para os próximos cinquenta anos. Quando nos interrogamos sobre o sentido do refletir sobre as cinco décadas vindouras necessitamos indagar qual a função da pós-graduação em Direito no Brasil no quadro de uma sociedade democrática. Encontra-se o sistema da pós-graduação em direito no Brasil em fase de crescimento e amadurecimento, sendo, aos cinquenta anos, o momento propício para que a comunidade acadêmica possa refletir sobre as suas perspectivas.

O significativo aumento nos últimos anos do número de programas de pós-graduação em Direito no país - inclusive com o estabelecimento dos mestrados profissionais - suscitam algumas indagações, que necessitam de uma resposta consistente por parte de todos envolvidos neste processo. Em 1995, de acordo com os dados da Fundação Capes, o sistema de pós-graduação em Direito tinha dezesseis cursos de mestrado e quatro cursos de doutorado; em 2001, somente seis anos após, o sistema passou a ter trinta e oito cursos de mestrado e onze de doutorado, além de cerca de trinta novas solicitações de autorização, em andamento na CAPES. De acordo com o Relatório de Avaliação 2013-2017 da Quadrienal 2017, o número de cursos de pósgraduação passou a 99 programas, distribuídos em 33 instituições públicas e $66 \mathrm{em}$ instituições particulares. Hoje, no ano de 2020, são, segundo a plataforma Sucupira, ${ }^{3}$ 132 Programas de Pós-Graduação em Direito no país, sendo que existem 109 cursos de Mestrado Acadêmico, 54 de Doutorado Acadêmico, 22 de Mestrado Profissional e, ainda, nenhum Doutorado Profissional. Esse salto exponencial está a exigir uma reavaliação dos métodos de ensino e de pesquisa pelas instituições, e, também, dos próprios critérios do sistema de avaliação da pós-graduação em Direito, pela CAPES.

\footnotetext{
1 Professor no PPGD da UNISINOS e professor visitante no PPGD da UERJ. Presidente do Fórum Filosofia, Ética e Sistemas Judiciais da EMERJ.

2 Professor da Escola de Direito da UNISINOS.

3 CURSOS Avaliados e Reconhecidos (Área de Conhecimento: Direito). In: Plataforma Sucupira. Brasília, DF, 2020. Disponível em: https://sucupira.capes.gov.br/sucupira/public/consultas/coleta/programa/ quantitativos/quantitativoAreaConhecimento.jsf?areaAvaliacao=26. Acesso em: 10 nov. 2020 .
} 
A indagação preliminar que paira sobre o aumento do número de ofertas de cursos de mestrado e doutorado resume-se em saber até que ponto o crescimento quantitativo corresponde a uma efetiva melhoria na qualidade da formação acadêmica, das pesquisas e da produção intelectual na área do conhecimento jurídico. Ao mesmo tempo em que se formulam essas perguntas, que se referem ao âmbito interno do ensino jurídico, permanece, também, de forma cada vez mais aguda, uma pergunta de caráter geral e que se reflete no contexto da própria sociedade: qual a repercussão social e a influência que o conhecimento produzido na pós-graduação em Direito tem tido no país, e quais as condições para que esse tipo de conhecimento e de pesquisas contribuam para a construção de uma sociedade democrática e justa?

A resposta ao primeiro conjunto de indagações tem sido dada, tentativamente, através do estabelecimento de um sistema de avaliação pela própria comunidade acadêmica dos programas de pós-graduação em Direito, que integram o sistema CAPES. A avaliação tem sido considerada, no âmbito da comunidade e nos órgãos governamentais, como sendo o processo mais seguro de legitimar o crescimento quantitativo do sistema de pós-graduação na área. O momento, portanto, é oportuno para que se reflita sobre as dimensões do sistema da pós-graduação em Direito e, também, para que se procure estabelecer critérios qualitativos comuns, que assegurem a progressiva integração dos novos cursos de mestrado e doutorado ao sistema de pósgraduação nacional. Por essa razão, torna-se necessário que essa reflexão contribua para fixar parâmetros qualitativos, garantidores da excelência do conhecimento científico produzido na área e de sua repercussão nos mecanismos sociais da nação. Trata-se, assim, de construir uma visão crítica do sistema, não para estagná-lo, mas para que possa ter desenvoltura e preencher a sua função no sistema educacional.

O crescimento do sistema de pós-graduação naárea do Direito correspondeu, sem dúvida, a uma demanda concreta da sociedade, que obrigou a uma reavaliação dos critérios de qualificação dos novos cursos, tanto por parte das universidades e instituições isoladas, quanto por parte dos órgãos governamentais. Os próprios números, que evidenciam esse crescimento do sistema, estão a exigir um necessário caveat neste processo de expansão, com a finalidade de fixar critérios balizadores de uma política de crescimento qualitativo na pós-graduação. Torna-se, assim, necessário situar a pósgraduação no ensino jurídico brasileiro e como as mudanças nela ocorridas apontam para a conformação progressiva do seu modelo ao encontrado nas demais áreas de conhecimento.

\section{A expansão da pós-graduação em Direito no Brasil}

O ensino jurídico iniciou-se, no Brasil, no alvorecer da nacionalidade, quando o Brasil, recém-saído das lutas pela independência, procurava firmar-se como um 
estado independente de Portugal. Os primeiros cursos de bacharelado em Direito foram criados, através de Carta de Lei de 11 de agosto de 1827, sancionada pelo imperador Dom Pedro I, e estabelecidos na Faculdade de Direito de Olinda e na Faculdade de Direito de São Paulo. Os cursos seriam regulados, dizia a lei imperial, pelos Estatutos do Visconde de Cachoeira, que fora redigido, em 1825, para um curso jurídico no Rio de Janeiro, tendo por objetivo estabelecer um sistema de ensino que pudesse formar "homens hábeis para serem um dia sábios magistrados e peritos advogados de que tanto se carece" e, também, dotar a jovem nação de "dignos Deputados e Senadores para ocuparem os lugares diplomáticos e mais empregos do estado" (VENÂNCIO FILHO, 1977, p. 31).

Na justificativa dos Estatutos, o Visconde da Cachoeira recomendava que não se adotassem na criação dos cursos jurídicos no Brasil os Estatutos da Universidade de Coimbra, pois, escrevia ele, ali havia uma demasiada erudição, baseada na profusão do estudo do Direito Romano, muito pouco estudando-se a legislação pátria e os princípios de Direito Natural, Público e das Gentes. Pretendia o Visconde de Cachoeira um outro tipo de curso, com outras finalidades, principalmente a de “...criar jurisconsultos brasileiros, enriquecidos de luminosas doutrinas e ao mesmo tempo úteis e que, pelo menos, o obtenham neste Curso bastantes e sólidos princípios, que lhes sirvam de guias nos estudos maiores e mais profundos que depois fizerem; o que é o mais que se pode esperar que obtenham estudantes de um curso acadêmico" (VENÂNCIO FILHO, 1977, p. 32). Os Estatutos, na opinião do mais completo especialista brasileiro sobre a história do ensino jurídico brasileiro, o prof. Alberto Venâncio Filho, constituíram, assim, a matriz de onde se originaram os textos regulamentares do nosso ensino do Direito. E é inegável que se o ensino das nossas faculdades tivesse seguido a concepção do Visconde de Cachoeira, provavelmente ter-se-ia evitado o ensino retórico e pouco prático, encontrado nas escolas de Direito durante o Império e a República. A necessária ligação entre o estudo dos princípios e a prática legal, e como esta última dependeria da perfeita apreensão dos primeiros, foi uma orientação, infelizmente, ignorada durante quase dois séculos pelo ensino jurídico brasileiro. Somente com os novos cursos de pós-graduação é que se veio recuperar o sentido do projeto original do Visconde de Cachoeira, dotandose o ensino da graduação e da pós-graduação em Direito de uma metodologia crítica, baseada na pesquisa do fenômeno jurídico.

Os cursos de graduação em Direito durante mais de um século foram o centro de formação dos bacharéis e juristas no Brasil, não havendo maiores preocupações com a pesquisa e a reflexão crítica na ciência do Direito. Com a Revolução de 1930, é que se iniciaram os primeiros cursos de pós-graduação, legalmente criados, pela Reforma Francisco Campos de 1931, através do Decreto 19.851, de 11 de abril de 1931. Neste documento legal, o curso de bacharelado em direito seria estruturado, como escreveu Francisco Campos, na sua exposição de motivos, em função de finalidades estritamente 
profissionais, buscando a formação de práticos- profissionais. Por essa razão, retirou-se da formação do curso de bacharelado todas as cadeiras que constituíssem disciplinas de formação doutrinária ou cultural, que desde a criação dos cursos jurídicos, em 1827, contribuíam, ainda que de forma incipiente, para uma abordagem crítica do fenômeno jurídico. Previa-se, entretanto, na nova legislação o estabelecimento dos cursos de doutorado, que teriam as seguintes características, nas palavras de Francisco Campos : "separado do curso de bacharelado, o curso de doutorado se destina especialmente à formação de futuros professores de Direito, no qual é imprescindível abrir lugar aos estudos de alta cultura, dispensáveis àqueles que se destinam apenas à prática de Direito. O curso de doutorado se distribui naturalmente em três grandes divisões: a do Direito Privado, a do Direito Público Constitucional e a do Direito Penal e Ciências Criminológicas" (apud VENÂNCIO FILHO, 1977, p. 306).

Os propósitos da Reforma Francisco Campos não deram, contudo, os resultados esperados, pois os cursos de doutorado, acabaram absorvendo os mesmos vícios metodológicos e pedagógicos encontrados nos cursos de bacharelado. Estabelecidos com o objetivo de formação científica do jurista, na prática constituíram-se em cursos que, em última análise, aprofundavam os conhecimentos hauridos no curso de bacharelado. A metodologia e a estrutura curricular dos cursos de doutorado obedeciam ao modelo tradicional das universidades europeias, com aulas discursivas, onde eram desenvolvidas matérias sob a perspectiva da dogmática estrita, aulas que se reduziam a longas conferências sem a menor preocupação com o questionamento do fenômeno jurídico. Caracterizava-se esse modelo, em outras palavras, por estudos aprofundados das grandes áreas dos estudos jurídicos, estudadas na graduação. Não se tratava, portanto, do desenvolvimento de estudos críticos do fenômeno jurídico, acompanhados por pesquisas teóricas e empíricas, mas a aceitação do formato do dogmatismo jurídico como sendo o campo epistemológico próprio para os estudos do doutorado.

A metodologia do ensino manteve também a tradição do ensino jurídico com aulas sendo dadas em função de pontos, com uma reduzida participação dos alunos. $\mathrm{O}$ trabalho de pesquisa, se assim poderia ser chamado, reduzia-se à consulta bibliográfica, e servia unicamente para demonstração de conhecimento, através de longas citações de autores, tidos como autoridades nos diferentes ramos da doutrina jurídica, sem que houvesse um mínimo de avaliação crítica do que se estava citando. Os cursos, portanto, conseguiam, quando muito, propiciar uma especialização em determinada área, com grande apego à dogmática, não havendo nenhuma preocupação problematizante ou teórica a respeito dos temas analisados. Não atendiam, portanto, aos objetivos estabelecidos por Francisco Campos, a formação de pesquisadores e professores de Direito.

Somente no final da década dos sessenta é que se iniciou a superação desse modelo pedagógico na pós-graduação em Direito, atendendo aos novos ventos que 
acabaram por determinar a Reforma Universitária de 1968, que visava, nas palavras de um de seus autores, o prof. Newton Sucupira, romper com a "cultura verbalística" que dominava o nosso ensino superior (s.d.: 42). Neste contexto de reforma e de adequação da universidade brasileira a um mundo onde a ciência e as tecnologias produziam profundas transformações socioculturais, as faculdades de Direito constituíram-se, entretanto, no foco de resistência à ideia da reforma universitária, principalmente, pelo apego a duas tradições: a cátedra e a autonomia da faculdade.

Algumas contestações ao modelo tradicional predominante no ensino jurídico fizeram-se sentir, no entanto, ainda nos meados da década dos anos sessenta, como foi o caso da experiência pioneira do Centro de Estudos e Pesquisas no Ensino do Direito - CEPED, criado na então Universidade do Estado da Guanabara, hoje Universidade do Estado do Rio de Janeiro (UERJ), em 1966. O CEPED tinha por objetivo aperfeiçoar o ensino jurídico e com a realização de pesquisas e a formação especializada. A atividade principal do CEPED residiu no desenvolvimento de um curso de pós-graduação, o curso de Advogados de Empresas, com vistas a uma análise interdisciplinar do Direito, sendo que o primeiro dos cursos foi realizado em 1967. A importância do CEPED não se resumiu, principalmente, em tratar as atividades de pós-graduação em Direito, sob uma ótica crítica e interdisciplinar, mas sim na ênfase temática e na metodologia própria do curso. Como escreveu o seu fundador, o prof. Alfredo Lamy Filho, tratava-se de transmitir aos alunos "não mais apenas os conhecimentos do Direito positivo, mas, sobretudo, a noção de que trabalham como profissionais do Direito sobre uma realidade em mutação, de que existe um permanente - agora agudo - processo de renovação do Direito e que é possível divisar o sentido desse processo" (apud VENÂNCIO FILHO, 1977, p. 326). Outro aspecto inovador do curso do CEPED residiu no método de ensino adotado. Para superar o método das preleções dogmáticas, repetitivas da leitura acrítica do direito positivo e de seus doutrinadores, propunha-se o método do problem method, a ser desenvolvido pelo estudo de casos, a serem problematizados com a ajuda de material de leitura, previamente distribuído.

O desafio enfrentado pela pós-graduação em Direito consistiu, assim, em superar o confronto entre a nova mentalidade que começava a dominar a universidade brasileira, que se encontrava formulada na Reforma Universitária de 1968 e no seminal Parecer 977/ 1965, do então Conselho Federal de Educação, mais conhecido como Parecer Sucupira, e a tradição encontrada nas faculdades de Direito. Enquanto as demais áreas do conhecimento adequavam-se ao espírito dos novos tempos, os cursos de doutorado em Direito continuaram a praticar um ensino defasado, e, progressivamente, esvaziaram-se, perderam a sua razão de ser e acabaram demonstrando a sua inviabilidade.

A atuação da Capes, desde a sua fundação, em 1951, voltara-se, principalmente, para as áreas da medicina, engenharia e ciências exatas, enfatizando as 
políticas de fomento em função da necessária reformulação de metodologias de ensino, do desenvolvimento de linhas de pesquisa e do conteúdo dos cursos de pós-graduação, que, como estabelecido no Parecer Sucupira, destinava-se, prioritariamente, à formação de professores e pesquisadores. Essa tendência foi incorporada na prática pelas mais diversas áreas do conhecimento, que se organizaram e modificaram os seus modelos acadêmicos em função dos critérios estabelecidos no Parecer Newton Sucupira. Depois da criação progressiva de cursos de pós-graduação nas áreas de ciências humanas e sociais, a partir do final dos anos sessenta, outras áreas, que não o Direito, passaram a participar ativamente do sistema CAPES.

A área do Direito permaneceu, assim, por cerca de duas décadas, alheia ao sistema de pós-graduação nacional. Como resultado, o sistema nacional de pósgraduação mostrou-se pelo menos reticente, quando começaram a aumentar o número de cursos de pós-graduação na área jurídica, que batiam, também, às portas das agências de financiamento para disputar com as demais áreas os recursos destinados ao fomento, bolsas de estudo e pesquisa na pós-graduação. Para que se tenha uma ideia desse afastamento da área do Direito das demais ciências sociais e humanísticas, no contexto do sistema de pós-graduação nacional, basta atentarmos para o fato de que, mesmo sendo o mais antigo curso de graduação no sistema do ensino superior brasileiro, somente depois de duas décadas teve um representante no CTC da CAPES, órgão responsável pelo apoio aos programas de pós-graduação no país, entre as 48 áreas que têm assento nesse órgão da administração superior.

Verifica-se, por outro lado, que a expansão da pós-graduação foi um fenômeno que ocorreu, na última década, de forma expressiva na área do Direito, mas não se reduziu a ela. $\mathrm{O}$ sistema de pós-graduação, como um todo, tem tido uma evolução quantitativa exponencial, de modo que, hoje, reúne todas as áreas de conhecimento.

$\mathrm{O}$ aumento do número de cursos de pós-graduação e de pós-graduados ocorreu concomitantemente ao crescimento dos cursos de bacharelado. Foi um crescimento, portanto, que não ocorreu sem motivos. Em primeiro lugar, na área do Direito são mais evidentes as causas do crescimento, pois deitam as suas raízes na política de ampliação de vagas na Universidade, a partir de 1968, que facilitou a abertura de novos cursos, com baixo investimento na infraestrutura e no corpo docente. Em segundo lugar, a demanda social por mais cursos de ensino superior e a criação de novas faculdades provocou, dentro do aparente controle exercido pelo regime militar nos assuntos da educação, um real descontrole da qualidade do ensino ministrado. Em terceiro lugar, a massificação do ensino superior, entendida como o acesso aos cursos superiores, ocorreu principalmente nas áreas das ciências humanas e sociais, onde o custo do investimento é significativamente mais baixo do que nas demais ciências. 
Neste ponto, é preciso destacar que a expansão da pós-graduação, ocasionada para atender às demandas dos cursos de bacharelado em Direito, não pode ser levada a reboque da graduação, ainda mais se levarmos em conta que a proliferação dos bacharelados conduz o ensino jurídico à massificação e, o que é mais grave, à mercantilização do conhecimento, visto que, de três décadas para cá, foram abertos cursos de Direito em todas as partes do Brasil, inclusive naquelas regiões que estavam tomadas por diversos cursos de bacharelado em Direito.

Os dados da Fundação CAPES são reveladores sobre a situação atual dos cursos de pós-graduação em Direito e de como a crescente demanda, atestada pelo número recorde de várias instituições solicitando autorização para a abertura de novos cursos de pós-graduação stricto sensu, está a exigir uma reflexão conjunta - professores, pesquisadores, administradores universitários, órgãos governamentais e entidades mantenedoras - para que se possa assegurar a elaboração de critérios comuns que garantam a qualidade e a pertinência social do sistema. Trata-se, antes de tudo, de considerar-se a distribuição dos cursos de pós-graduação em função das áreas geográficas e de como essa distribuição poderá atender no primeiro momento à demanda dos cursos de bacharelado por mestres e doutores. Isto sem descurar-se da finalidade última da pósgraduação que é a de formar, além de professores, pesquisadores na área.

A distribuição geográfica desses cursos não é de maneira alguma equânime, concentrada no Sul e no Sudeste, havendo regiões extremamente prejudicadas, sem nenhuma possibilidade de aperfeiçoamento na área, como o Norte e o Centro-Oeste. Todo esse sistema volta-se, no momento, para atender à demanda advinda dos cursos de graduação, que aumentaram em número e, tendo em vista as experiências adquiridas na do ENADE, estão a obrigar a uma efetiva melhoria qualitativa no ensino de graduação, que deverá ser consequência da formação de professores e também do desenvolvimento de um tipo de ensino na graduação que forme profissionais, que, pela própria natureza do Direito, deverão ter uma visão crítica e interdisciplinar do fenômeno jurídico. O número crescente de cursos de graduação, hoje na faixa de 1.200 cursos - enquanto que, nos anos 90, não passavam de três centenas de cursos -, faz com que a pós-graduação adquira uma dupla importância: a primeira, a de formação de professores, e a segunda a de permear as atividades de formação dos alunos da graduação, através de projetos de Iniciação Científica.

A pós-graduação stricto sensu pode contribuir com a graduação no que tange à formação dos novos profissionais do Direito, desde advogados até aqueles que vão procurar as carreiras públicas. Pode contribuir para o perfil do egresso, ao ensinar, criticamente, o Direito, para que o aluno possa conhecer os fundamentos basilares do sistema normativo, buscando a justiça e a equidade nos casos em que atuar. A verve crítica da pós-graduação deve reverberar nas salas de aula da graduação, na medida em 
que os seus docentes são e foram formados nos seus cursos de mestrado e doutorado - ou assim deveria ser em absolutamente todas as faculdades e Direito. Assim, estudantes da graduação poderão compreender o fenômeno jurídico a partir de saberes transdisciplinares e, com isso, propor soluções razoáveis ao caso concreto; poderão desenvolver competências e habilidades que impliquem no contínuo aprendizado

Enquanto isto, simultaneamente, a política educacional do governo retira das instituições públicas as condições para o seu crescimento, fazendo com que os alunos egressos do sistema de bacharelado em Direito das universidades públicas acabem indo procurar fazer a pós-graduação nas universidades privadas. O sistema do ensino da pósgraduação caminha, assim, para o fortalecimento dos cursos nas instituições privadas, que deverão privilegiar a dimensão da qualidade, para que possam atender às exigências de qualificação do mercado e da avaliação das agências governamentais. Observe-se que o processo de enfraquecimento das instituições públicas do ensino pós-graduado na área jurídica abre, como era de se esperar, novas perspectivas para as entidades privadas, que tenham uma visão mais aprimorada e sofisticada da pós-graduação. $\mathrm{O}$ enfraquecimento do sistema federal na área coloca à disposição do mercado quadro de professores e pesquisadores qualificados, que poderão contribuir para fortalecer os cursos de instituições privadas, que receberão mestres, doutores e professores egressos do sistema público de ensino. Com isto esses programas irão, assim, atingir o nível de qualificação e reconhecimento social, até então reservado às instituições públicas.

Aparece nos meios acadêmicos jurídicos, em virtude dos fatores acima analisados, uma saudável preocupação com a necessária e inadiável qualificação do sistema de pós-graduação em Direito, que pode ser evidenciada por fatores internos e externos às instituições de ensino. De um lado, interna corporis, constata-se uma progressiva profissionalização dos professores de Direito, que passaram a ter regimes de trabalho que lhes permitem, paulatinamente, a dedicação ao ensino e à pesquisa jurídica; este fenômeno acontece, principalmente, naquelas instituições privadas que investiram na qualificação dos seus cursos de pós-graduação. Externamente, delineia-se um sistema de avaliação do sistema de pós-graduação que vem aperfeiçoando e afinando os seus critérios avaliativos nos últimos cinco anos. Pouco a pouco, ganha corpo no sistema da pós-graduação critérios de qualificação, que baseados em dados quantitativos e qualitativos, deverão definir o perfil do ensino da pós-graduação em Direito e separar o joio do trigo no processo de crescimento do sistema.

Neste contexto, é que a comunidade acadêmica da área tem participado de forma crescente na definição dos caracteres diferenciadores da avaliação na pós-graduação em Direito, servindo esses critérios para aperfeiçoar o sistema de avaliação da Capes. O Comitê da Área de Direito da CAPES, encarregado da avaliação trienal do sistema, baseado nas indicações feitas pela comunidade acadêmica no workshop, promovido 
pela CAPES, em dezembro de 2000, e no CONPEDI, estabeleceu, pela primeira vez na história da pós-graduação em Direito, critérios públicos para a avaliação da área. Em outras palavras, as perspectivas do sistema de pós-graduação em Direito encontram-se diretamente ligadas ao processo de avaliação a ser realizado pela própria comunidade e não podem ser deixadas ao voluntarismo das forças de mercado ou ao decisionismo burocrático, sob pena de tornar-se irrelevante face às demandas da sociedade.

\section{As perspectivas da pós-graduação em Direito}

A análise das perspectivas da pós-graduação em Direito deve considerar dois aspectos: em primeiro lugar, o que se entende e quais os objetivos dos cursos de pós-graduação, como se encontram definidos nos documentos legais pertinentes; em segundo lugar, quais seriam os critérios mais gerais e universais que poderiam contribuir para o estabelecimento de critérios mínimos rigorosos, que permitam o crescimento do sistema da pós-graduação, obediente às características do ensino jurídico, mas integrado às exigências e critérios qualitativos das demais ciências, principalmente das ciências sociais e humanas.

Um aspecto da questão é o da tendência evidenciada pela política governamental de simplificar e expandir os mestrados, concentrando em algumas instituições a responsabilidade pelos cursos de doutoramento. Esse novo viés da política educacional fez com que surgisse a proposta de cursos interinstitucionais ou a distância, que viriam suprir a necessidade de formação urgente de mestres, e principalmente, de doutores que possam consolidar os cursos de mestrado. Permanece, então, mais atual do que nunca os dois desafios encontrados no contexto atual: como atender à necessidade de crescimento do sistema, mantendo a sua qualidade e a excelência acadêmica.

Torna-se necessário, portanto, que se tenha uma compreensão precisa da natureza da pós-graduação stricto sensu e quais as implicações dessa conceituação para os cursos de mestrado e doutorado na área do Direito. A pós-graduação, como se encontra definida no parecer do prof. Newton Sucupira, acima referido, entende-se como sendo constituída por dois níveis de formação: o mestrado e o doutorado, sendo o primeiro caracterizado como a atividade voltada para o aperfeiçoamento e aprofundamento dos estudos e, o segundo, pelo envolvimento do aluno em atividades de pesquisa destinadas à elaboração de uma tese final. A pós-graduação stricto sensu apresenta, nos termos do Parecer Sucupira, as seguintes características: é uma atividade com características acadêmicas e de pesquisa, não profissional, portanto, mesmo atuando em áreas particularmente profissionais, a pós-graduação mantém a sua natureza científica; a pós-graduação confere grau acadêmico; a pós-graduação possui uma sistemática que se destina a formar o estrato superior na hierarquia dos cursos, que constituem a universidade. Define, assim, o Parecer Sucupira a pós-graduação stricto sensu: “o ciclo 
de estudos regulares em segmento à graduação, sistematicamente organizados visando desenvolver e aprofundar a formação adquirida no âmbito da graduação e conduzindo à obtenção de grau acadêmico". (Parecer Sucupira, 1965). Constata-se, portanto, que os cursos de mestrado e doutorado se destinam, primeiramente, à formação de pessoal acadêmico para as universidades, vale dizer, professores e pesquisadores, e somente incidentalmente servem para o aperfeiçoamento técnico-profissional.

Essa conceituação de pós-graduação tornou-se aceita pelas áreas de conhecimento das universidades brasileiras, tendo sido com grande dificuldade recepcionada no âmbito das faculdades de Direito. A mudança radical no sistema de ensino de Direito ocorrida no último decênio consistiu, principalmente, na aceitação progressiva dessa concepção de pós-graduação e como os modelos dos programas de pós-graduação em Direito passaram a organizar-se tendo em vista a definição do Parecer Sucupira.

Em função das exigências de qualificação do ensino superior de graduação, estabelecidas pela Lei de Diretrizes e Bases da Educação Nacional (Lei n 9.394/ 96, art. 52, II), que estabeleceu para as instituições de ensino superior, públicas e privadas, um prazo, até 2004, de qualificação de 1/3 do seu corpo docente com a titulação acadêmica de mestrado ou doutorado, a demanda tornou-se aguda por cursos de pós-graduação, que venham qualificar o corpo docente dos cursos de bacharelado em Direito. Para atender às exigências da legislação, o sistema federal de ensino estabeleceu metas para que o sistema de pós-graduação possa atender à demanda de qualificação da graduação, para isto passando a avaliar os cursos de pós-graduação em função de um padrão, comum a todas as instituições públicas ou privadas. A intenção do poder público em criar condições para o crescimento da pós-graduação expressou-se de forma clara na fixação de metas para a qualificação pós-graduada dos docentes do sistema público de ensino superior (veja-se, por exemplo, o Protocolo para a Expansão do Sistema Público de Ensino Superior, de 15 de dezembro de 1998), que pretende passar, no sistema federal, do índice de 67\%, encontrado em 1997, para 90 \% dos docentes com pós-graduação stricto sensu, em 2002.

Surge, então, neste contexto de modernização dos formatos acadêmicos da pós-graduação em Direito, uma questão emergente e que tem a ver com o aumento da demanda e da oferta de cursos de pós-graduação. Um dos problemas cruciais neste processo de crescimento consiste em adequar-se a consolidação dos cursos de mestrado à necessidade de professores titulados como doutores. A solução inicial, em várias áreas do conhecimento, inclusive a do Direito, foi a de enviar mestres para fazer seus cursos de doutorado fora do país. Os estudos de pós-graduação no exterior, na área do Direito, receberam o seu impulso inicial nas atividades do CEPED, tendo tido, desde então, em relação às demais áreas do conhecimento, uma baixa demanda de bolsas. No entanto, a 
opção de estudos no exterior torna-se, atualmente, cada vez mais difícil, tendo em vista a redução significativa dos recursos governamentais para esse tipo de fomento.

Tendo em vista a carência de mestres e doutores, a política governamental tem permitido algumas soluções, que necessitam ser melhor avaliadas pela comunidade jurídica e pelas agências governamentais de fomento. A primeira delas é a implementação do mestrado profissional, que sem tirar o caráter acadêmico do curso, serviria para a titulação de mestres em menor período, sendo aplicável nas áreas de conhecimento com forte conotação profissional, como seria o caso do Direito. A comunidade jurídica, entretanto, posicionou-se, em princípio, no CONPEDI do Rio de Janeiro, em 2000, contrária ao mestrado profissional no Direito. No entanto, o tema foi retomado para que a comunidade jurídica pudesse avaliar a natureza deste tipo de mestrado e sua possível, ou recomendável, integração no sistema do ensino jurídico. Hoje já são 22 cursos de mestrado profissional em Direito. A segunda solução adotada por várias instituições têm sido a de realizar, acoplados aos cursos de mestrado, cursos de doutorado interinstitucionais ou a distância. As características do ensino a distância na pós-graduação em Direito, por seus aspectos inovadores, também deverão ser discutidas pela comunidade, sendo que o Ministério da Educação, tendo em vista a proliferação dos cursos a distância, terminou regulamentando o seu funcionamento, o que exigirá uma reformulação do sistema.

Em razão da pandemia de Covid-19, que obrigou as universidades a migrarem para o ensino remoto, verifica-se uma tendência para ampliar o uso de tecnologias que possibilitem a educação a distância. Disso decorrerão diversos desafios, que, para serem mitigados, talvez possam ser melhor sedimentados num modelo híbrido que mescle o presencial com a educação a distância. O fato é que o pós-pandemia imporá à comunidade acadêmica um amplo debate sobre o uso do ensino a distância, em especial quando em paralelo com a pesquisa.

Levando-se em consideração essas dimensões da pós-graduação em Direito - a da sua conceituação, a possível adaptação a um modelo de ensino a distância e à necessidade de formar-se o mais rapidamente possível quadros pós-graduados -, o Conselho Nacional de Educação baixou resolução que estabelece normas para o funcionamento dos cursos de pós-graduação (Resolução $\mathrm{n}^{\circ} 1$, de 3 de abril de 2001), fazendo com que o processo de autorização, reconhecimento e renovação de reconhecimento, tanto dos cursos presenciais, como os dos cursos a distância, passem a obedecer normas estritas, que ordenem o processo de crescimento do sistema. Contempla, também, a referida Resolução (art. $5^{\circ}$ ), em caráter excepcional, a obtenção do título de doutro mediante a defesa direta de tese, sem exigência de créditos, em instituição com doutorado reconhecido.

A referida resolução do $\mathrm{CNE}$, deixando-se de lado no momento os aspectos extremamente discutíveis sobre a regulamentação dos cursos de ensino à distância e do doutorado direto, serve, entretanto, como um passo inicial e referencial seguro, 
principalmente para uma área como a do Direito, que se inicia na implantação de um sistema acadêmico na pós-graduação. Em primeiro lugar, o CNE sujeita a autorização dos cursos de pós-graduação stricto sensu ao projeto acadêmico aprovado pelo Conselho; os cursos que se iniciaram antes da autorização referida, devem formalizar os seus projetos até, no máximo, 12 meses após o início de suas atividades docentes. A Resolução nº 1/ 2001 do CNE enfatiza o caráter acadêmico da pós-graduação stricto sensu - vale dizer, como as linhas de pesquisa constituem a espinha dorsal dos cursos de mestrado e doutorado - ao estabelecer: "é condição indispensável para a autorização, o reconhecimento e a renovação de reconhecimento de curso de pós-graduação stricto sensu a comprovação de prévia existência de grupo de pesquisa consolidado na mesma área de conhecimento do curso." (Resolução $n^{\circ} 1$, de 3 de abril de 2001, art. $1^{\circ}, \S 5^{\circ}$ ). A questão da pesquisa jurídica torna-se, assim, fator essencial na qualificação dos cursos de mestrado e doutorado na área, não se podendo admitir nem a solicitação de novos cursos ou, mais grave ainda, o seu reconhecimento, sem que as suas atividades acadêmicas sejam conduzidas por um núcleo de professores e pesquisadores em torno de linhas de investigação comuns.

A Resolução $n^{0} 1 / 2018$ estabelece diretrizes para a oferta dos denominados cursos de especialização e, com isso, fixa critérios para que se possa diferenciar os cursos de pós-graduação stricto sensu, oferecidos a distância dos cursos de pós-graduação lato sensu, exigindo que, além de serem oferecidos por instituições para isto credenciadas pela União, como estabelece o art. 80, § $1^{\circ}$ da Lei n ${ }^{\circ}$ 9.394/ 1996, obedeçam, também, as exigências da referida resolução, o que inibe a proliferação de cursos lato sensu sem o mínimo de condições de formação acadêmica e de pesquisa.

O amadurecimento de um núcleo de pesquisas na área do Direito representa, assim, um passo adiante na superação de um modelo reducionista e dogmático da ciência jurídica, isto é, na superação daquele modelo "nitidamente dogmático", conforme nos alerta o professor Tércio Sampaio Ferraz Jr.:

O ensino jurídico, como dissemos, tem tido uma orientação nitidamente dogmática. Assim, por exemplo, quando se pensa em reformá-lo, logo pensamos em reforma do currículo (mínimo). O enfoque curricular não trabalha com o modelo pergunta-resposta, na medida em que isola um dos seus termos e o torna exclusivo. Acentua, pois, o aspecto resposta, de modo unilateral, propondo-se a enumerar um mínimo de disciplinas, o que faz do ensino um modelo quase-axiomático (mínimo de proposições verdadeiras - leia-se disciplinas básicas - que devem ser ministradas). (FERRAZ JÚNIOR, 2006, p. 6).

Para quebrar essa lógica dogmática, supõe-se o entendimento do fenômeno do Direito inserido na complexidade das relações sociais, características do século XXI, o que implica em abordagem interdisciplinar de sua temática, como destaca 
Ferraz Jr. ao apontar para um modelo pergunta-resposta: "Sugerimos assim, a adoção do modelo pergunta-resposta, que nos obriga a ver o direito como um conjunto de questões fundamentais, que atravessam as diferentes disciplinas, dando-lhe uma unidade dinâmica e ativa." (FERRAZ JÚNIOR, 2006, p. 7). A abordagem interdisciplinar exige dos cursos stricto sensu uma compreensão do fenômeno jurídico que não se reduza ao tecnicismo e à profissionalização das carreiras jurídicas. Trata-se de habilitar seus discentes a uma atitude crítica e analítica, que transita entre problemas de fundamentação ético-filosófica e questões que envolvem a interação do discente com problemas sociais, políticos e éticos, e que exigem do discente o envolvimento com problemas de maior complexidade.

A formação de pesquisadores na área exige autonomia intelectual em paralelo com os valores da pessoa humana que estão, no fundo, elencadas na Constituição de 1988; exige a adoção do paradigma humanista e republicano contido no bojo do próprio Estado Democrático de Direito. Logo, a pesquisa jurídica, condição básica para a qualificação de um curso de pós-graduação na área, deve ser fundada no estudo de disciplinas de caráter geral e crítico, como a filosofia do Direito, a antropologia, a sociologia jurídica, a história, a economia e a metodologia científica.

O novo professor de Direito, e, em consequência, o novo profissional, a ser formado no século XXI, estará, assim, habilitado a lidar com o sistema normativo dentro de uma perspectiva crítica, que assegure a utilização do Direito como um instrumento de mudança e qualificação da sociedade e não como um fator de retrocesso e conservadorismo. O professor-pesquisador, comprometido com o Estado Democrático de Direito, deve mostrar a seus alunos que o Direito é um instrumento de transformação social e atuar, no campo prático, sempre guiado a propor soluções inovadoras. A pesquisa deve ter impacto na sociedade; deve ser capaz de alterar a realidade social, de modo que o aluno precisa estar apto a propor soluções sempre que diante de problemas jurídicos.

\section{Considerações Finais}

Trata-se, assim, de modelar o ensino da pós-graduação em direito no quadro de um estado democrático de direito. O Preâmbulo da Constituição Brasileira de 1988, estabelece que o Estado Democrático de Direito se destina a assegurar "exercício dos direitos sociais e individuais, a liberdade, a segurança, o bem-estar, o desenvolvimento, a igualdade e a justiça". No art. $5^{\circ}$, a Constituição Federal elenca as liberdades e garantias individuais, enquanto que, no art. $6^{\circ}$, estabelece quais são os direitos sociais: a educação, a saúde, o trabalho, a moradia, o lazer, a segurança, a previdência social, a proteção à maternidade e infância e a assistência aos desamparados. Esses são valores considerados pelo texto constitucional como "valores supremos". Observa-se, entretanto, na doutrina e na jurisprudência, uma profunda e sintomática dificuldade em lidar com a ideia e o 
regime jurídico desses valores supremos, pois, para tanto, o jurista necessita de uma abordagem ético-filosófica sobre os direitos fundamentais e os direitos humanos.

A promulgação da Constituição de 1988, entretanto, provocou em sua aplicação, pelos tribunais, uma necessária avaliação de como inserir no quadro da pósgraduação em direito uma reflexão crítica e analítica dos valores de nossa Constituição. Passou-se a examinar qual a possível contribuição da filosofia do direito para o direito e, especificamente, para a aplicação do texto constitucional e das leis positivas pelo poder judiciário. Existem razões para que o estudante de direito deva aplicar-se nesse tipo de estudo teórico, abstrato, aparentemente distante dos códigos e da vida dos tribunais? Por que, enfim, estudar a filosofia do direito?

O interesse pela temática da filosofia do direito é um fenômeno cultural e político que se manifesta no espaço público de todas as sociedades contemporâneas. Nações tradicionais, com culturas jurídicas sedimentadas, bem como nações recentemente estabelecidas, reclamam uma grande dose de reflexão filosófica sobre o Direito e a Lei. Qual a causa para esse fenômeno que se manifesta de modo universal? A resposta encontra-se, provavelmente, na característica comum às sociedades democráticas, que têm como princípio nuclear o exercício da liberdade e a garantia da igualdade, tendo o Direito a função de ordenar o exercício da liberdade individual, limitar o poder do Estado e assegurar a justiça social, características próprias do estado democrático de direito. Por essa razão, as últimas décadas presenciaram uma maré crescente de democratização, que substituiu não somente os regimes autoritários, mas modificou a própria natureza do estado liberal de direito. O revigoramento e o estabelecimento de instituições democráticas exigiram para o seu funcionamento uma atenção permanente para a questão da liberdade, da igualdade, da responsabilidade, dos direitos humanos e da justiça, temas predominantes na reflexão filosófica sobre o fenômeno jurídico. Neste quadro é que a pós-graduação em direito assume um papel essencial na conformação de um estado democrático de direito.

\section{Referências}

ADEODATO, João Maurício. A OAB e a massificação do ensino jurídico. In: SILVEIRA; Vladimir Oliveira da; SANCHES, Samyra Haydêe Dal Farra Naspolini; COUTO, Mônica Bonetti (org.). Educação jurídica. São Paulo: Saraiva, 2013.

BASTOS, Aurelio Wander. O Ensino Jurídico no Brasil. Rio de Janeiro: Lúmen Júris Lida, 1998. FERRAZ JUNIOR, Tercio Sampaio. Reforma do ensino jurídico: reformar o currículo ou modelo? Cadernos FGV Direito Rio: Educação e Direito, v. 2. Rio de Janeiro, set. 2006. 
CURSOS Avaliados e Reconhecidos (Área de Conhecimento: Direito). Plataforma Sucupira. Brasília, DF, 2020. Disponível em: https:/sucupira.capes.gov.br/sucupira/public/consultas/coleta/ programa/quantitativos/quantitativoAreaConhecimento.jsf?areaAvaliacao=26. Acesso em: 10 nov. 2020.

MINISTÉRIO DA EDUCAÇÃO. Resolução da Câmara de Educação Superior do Conselho Nacional de Educação (CNE), Resolução n. ${ }^{\circ}$ 1, de 3 de abril de 2001. Estabelece normas para o funcionamento de cursos de pós-graduação. Brasília, DF: MEC, 2001. Disponível em: http:// portal.mec.gov.br/dmdocuments/rces001_01.pdf. Acesso em: 13 nov. 2020.

MINISTÉRIO DA EDUCAÇÃO. Resolução da Câmara de Educação Superior do Conselho Nacional de Educação (CNE), Resolução n. ${ }^{\circ}$, de 6 de abril de 2018. Estabelece diretrizes e normas para a oferta dos cursos de pós-graduação lato sensu denominados cursos de especialização, no âmbito do Sistema Federal de Educação Superior, conforme prevê o Art. 39, § $3^{\circ}$, da Lei $n^{\circ}$ 9.394/1996, e dá outras providências. Brasília, DF: MEC, 2001. Disponível em: http://portal.mec. gov.br/index.php?option $=$ com_docman\&view $=$ download\&alias=85591-rces001-18\& category_ slug=abril-2018-pdf\&Itemid=30192. Acesso em: 13 nov. 2020.

SUCUPIRA, Newton. A Condição Atual da Universidade Brasileira e a Reforma Universitária Brasileira. Vassouras: Fundação Educacional Severino Sombra, 1976.

SUCUPIRA, Newton. Definição dos Cursos de Pós-graduação. Revista Brasileira de Estudos Pedagógicos, v. 44, n. 100, p. 67-86, dez. 1965. Parecer CFE 977/1965.

VENÂNCIO FILHO, Alberto. Das Arcadas ao Bacharelismo. São Paulo, Editora Perspectiva, 1977. 